\title{
SOLOS COESOS COMO FATOR DE RESISTÊNCIA À AGRICULTURA MODERNA NO OESTE BAIANO: UMA ABORDAGEM ESCALAR
}

\author{
COHESIVE SOILS AS A FACTOR IN RESISTANCE TO MODERN AGRICULTURE \\ IN WESTERN BAHIA: A SCALAR APPROACH
}

\author{
SOL COHÉRENT COMME FACTEUR DE RÉSISTANCE À L'AGRICULTURE \\ MODERNE AU BAHIA OCCIDENTAL: UNE APPROCHE SCALAIRE
}

\author{
Joildes Brasil - Universidade Federal de Goiás - Goiânia - Goiás - Brasil \\ joildesbrasil@yahoo.com.br
}

\begin{abstract}
Resumo
0 objetivo principal deste artigo é discutir como um fator natural, neste caso o solo, mesmo em meio ao aparato tecnológico disponível atualmente, pode se apresentar como resistência à inserção de novas áreas ao processo de modernização agrícola. Para atender esse propósito se faz necessário abordar a pertinência da escala dos mapeamentos pedológicos no Brasil e a possibilidade de mascaramento, a depender da escala, de peculiaridades ou anomalias pedológicas. Para essa discussão, o recorte espacial utilizado será uma fazenda experimental, localizada no Oeste da Bahia, que apresentou problemas com a plantação de eucalipto, devido à presença, antes desconhecida, de um solo atípico para a região, conhecido como solo coeso. Este tipo de solo é caracterizado basicamente por apresentar uma camada ou horizonte extremamente compacto, com alto grau de consistência (por elevada coesão), quando seco, e friabilidade, quando úmido. Tal característica pode proporcionar dificuldade no crescimento das raízes e problemas de aeração no solo. Espera-se que este artigo possa contribuir na discussão sobre os mapeamentos pedológicos atuais do Brasil e sobre a escala de abordagem desses mapas, já que esta última tem relação direta com a intenção e intervenção no espaço geográfico.

Palavras-chave: mapeamento, escala, solos coesos, modernização agrícola.
\end{abstract}

\section{Abstract}

This paper aims to discuss how natural factors, in this case the soil, even with the technology available nowadays, can be a resistance factor to the insertion of new areas to the process of agriculture modernization. To meet this purpose, it is necessary to address the pedological maps scale appropriateness in Brazil and the possibility of masking, depending on the peculiarities or pedological anomalies scale. For this discussion, the space used will be an experimental farm, located in the west of Bahia State, that presented problems with the eucalyptus plantation, due to the presence of the Cohesive soil. This type of soil is characterized for having an extremely compact layer, with high consistence degree, when dry, and friability, when it is humid. This characteristic can make it more difficult for root development and cause problems of soil aeration. So, it is expected that this paper can contribute to the discussion on actual soil mappings in Brazil and maps approach scale, considering that the latter is directly related to the intention and intervention in geographic space.

Key words: mapping, scale, soil with cohesion, agriculture modernization.

\section{Résumé}

L'objectif principal de cet article est de discuter comment un facteur naturel, dans ce cas le sol, même si, au beau milieu de l'appareil technologique disponible actuellement, peut se présenter comme résistance à l'inclusion de nouveaux secteurs au processus de la modernisation agricole. Pour se réunir que le but est nécessaire pour adresser la pertinence de l'échelle des tracés pédologiques au Brésil et de la possibilité de masquage, dépendre de l'échelle des particularités ou des anomalies de sol. Pour cette discussion, le secteur spatial utilisé sera une station expérimentale, située dans le Bahia occidental, qui a présenté des problèmes avec la plantation de 
l'eucalyptus, dû à la présence, avant inconnu, un sol atypique pour la région, connu en tant que sol cohérent. Ils sont caractérisés principalement en présentant un contrat de couche ou d'horizon extrêmement, avec un niveau élevé de cohérence (par cohésion élevée), une fois secs, et friabilité si moites. Cette caractéristique peut fournir la difficulté dans la croissance des racines et des problèmes de l'aération dans le sol. De cette façon, on l'espère que cet article peut contribuer dans la discussion sur le courant pédologique de tracés du Brésil et sur l'échelle de l'approche de ces cartes, puisque ce dernier a des relations directes avec l'intention et l'intervention dans l'espace géographique.

Mots-clés: cartographie, échelle, sols cohérents, modernisation agricole.

\section{Considerações iniciais}

Com o avanço das técnicas ao longo da história, a ação do homem passou a ser cada vez mais intensa na natureza, imiscuindo marcas indeléveis no estrato geográfico da Terra. Todavia, essa relação entre Homem $\mathrm{x}$ Natureza nem sempre foi estabelecida dessa forma. De acordo com um argumento determinístico, no meio natural (ou o período pré-técnico), a ação antrópica estava subjugada a intempéries naturais, ou seja, a Natureza ditava as regras.

A partir da evolução do homo faber (expressão latina para o homem primitivo que produz utensílios) para o homo sapiens (homem racional e inteligente), as técnicas e o conhecimento foram se aperfeiçoando e, nesse momento, o jogo se inverte, a Natureza agora é fonte de possibilidades para a ação humana.

Entre as atividades que melhor representam essa relação entre o homem e seu habitat, está a agricultura, atividade que marca a transição do homem primitivo de seu caráter nômade para o caráter sedentário. Concomitante a isso, surge o interesse em conhecer as características do solo (ainda que não cientificamente), para que dessa forma o homem possa melhor utilizar esse recurso natural, permitindo a sobrevivência da sua espécie.

Atualmente, a ciência responsável pelo estudo sistemático do solo é conhecida como Pedologia, e seus estudos tem despertado o interesse de diversas vertentes científicas, como a Agronomia, a Engenharia, a Geologia e, em destaque aqui, a Geografia, seja em âmbito nacional ou internacional.

Os estudos dessa ciência, juntamente aos avanços tecnológicos, permitiram o melhoramento das técnicas e, consequentemente, das formas de uso e ocupação do espaço geográfico. Todavia, a utilização dessas novas técnicas tem se apresentado de forma paradoxal, ou seja, tem sido espacializadas de maneira contraditória. 
Um exemplo dessa contradição está, por exemplo, nas formas do uso do solo. A partir do que se chamou de "Revolução Verde" (ocorrida na década de 1960), houve um grande crescimento na produção de alimentos, visto que já eram então encontrados no mercado novos produtos como fertilizantes, corretivos, defensivos agrícolas e sementes geneticamente selecionadas. A utilização dessas técnicas modernas na agricultura potencializou a produção, engendrando o que hoje é conhecido como agricultura científica e/ou moderna.

Contraditoriamente, a utilização exacerbada dos solos tem provocado sérios problemas ambientais, como a perda da biodiversidade pelo desmatamento indiscriminado, pela erosão acelerada, assoreamento, lixiviação, diminuição das reservas hídricas, entre outros impactos. Este problema da degradação envolve, então, a perda produtiva do solo, do equilíbrio do meio ambiente, assim como também reduz a renda financeira do proprietário da área degradada, tornando-se igualmente um problema socioeconômico.

Uma alternativa para um melhor uso e ocupação dos solos está no conhecimento da dinâmica natural deste recurso. O instrumento base para isso é o mapa de solos, que permite a identificação, classificação e localização dos tipos de solos de uma determinada área. Todavia, o processo de mapeamento, que se inicia no campo com a coleta da amostra de solo, até a compilação dos dados no mapa final, requer muito trabalho (de campo, laboratório e gabinete).

A dificuldade presente no processo de mapeamento faz com que os mapas atuais de solos no Brasil se apresentem, na sua grande maioria, em escalas pequenas (1:500.000), em razão, principalmente, da falta de levantamentos detalhados sobre os solos nacionais. Essa carência de mapeamentos pedológicos em grande escala que contemplem a realidade regional/local, pode em alguns casos apresentar informações falaciosas, ou ainda mascarar peculiaridades ou anomalias do solo.

Nesta discussão sobre mapeamentos de solos, coloca-se em evidência outro velho debate ainda atual na Geografia: o "problema da escala". Todavia, é preciso entender que, a priori, o problema não é a escala em si, muito menos a dicotomia entre escala geográfica e escala cartográfica. A questão está no entendimento do próprio conceito de escala e na compreensão de que, a depender do fenômeno que se pretende observar, diferentes tipos de escala (ou níveis de análise) se fazem necessários. 
Um estudo de caso em particular permitirá melhor discutir esta problemática em torno da escala, e mostrar como ela interfere na interpretação da realidade, "condicionando tanto a natureza das observações quanto a imagem que delas se dará" (Racine et al., 1983, p. 124). Este estudo terá como recorte espacial uma fazenda experimental, localizada no município de Cotegipe, no Oeste da Bahia, que apresentou problemas no cultivo de eucalipto, devido à presença de um solo atípico para a região (não identificado nos mapas atuais), o qual é conhecido como solo coeso, caracterizado pela presença de um horizonte extremamente endurecido nos primeiros centímetros do solo, que dificulta o crescimento radicular (Giarola, 2002).

A partir do que foi perscrutado, o objetivo deste artigo é mostrar que, mesmo com todo aparato tecnológico hoje disponível na região Oeste da Bahia, que é representado principalmente pelos grandes empresários rurais e pela rede de multinacionais relacionadas ao agronegócio presentes na região, fatores naturais, como o exemplo dos solos coesos, podem construir resistências naturais/locais a esse tipo de ocupação, podendo (ou não) dificultar que novas áreas sejam incluídas no processo de modernização agrícola.

A metodologia utilizada neste trabalho se deu por meio de um levantamento bibliográfico (livros, artigos, monografias, dissertações e teses) relacionado a questões como: o desenvolvimento da agricultura moderna no Oeste Baiano, o problema da escala nos mapeamentos de solos, as resistências naturais a esse tipo de uso e ocupação proposto (ou imposto) pelo agronegócio. Por fim, foi analisado um estudo de caso, resultado dos dados do trabalho monográfico de conclusão de curso que trata de Classificação e Mapeamento de Solos da Carta SC 23-Z-C-II-3-SO (Brasil, 2011), como forma de exemplificar a problemática dos mapeamentos de solos e a escala de abordagem.

\section{Agricultura moderna no Oeste da Bahia: gênese do processo}

A região do Oeste Baiano tem passado por um processo relativamente rápido de mudanças desde o final da década 1980 principalmente, no que diz respeito ao uso e apropriação do solo. Essa mudança se deu principalmente com a expansão dos fronts agrícolas, ou seja, com a ampliação das atuais áreas onde está presente a chamada agricultura moderna (Frederico, 2009). 
Para entender essa ocupação recente das áreas do cerrado baiano pelo agronegócio, é preciso se reportar à história, com destaque para o projeto de interiorização do Brasil promovido pelo Plano de Metas (19561961), do então presidente da República Juscelino Kubitschek. O grande objetivo era ocupar as áreas "anecúmenas” da região Centro-Oeste do país, processo que foi impulsionado principalmente com a criação de Brasília.

Inicialmente, essa nova territorialização foi financiada pelo Governo, que modernizou e expandiu "as vias de transporte, as bases energéticas e as telecomunicações” (Frederico, 2009, p. 45). Essas ações aconteceram concomitantes a um segundo processo, que foi a migração em massa de um contingente populacional (oriundos da região Sul, Sudeste, e principalmente do Nordeste) para essa região (Haesbaert, 1996; Mondardo, 2010).

A partir da década de 1970, percebem-se as primeiras consequências desse processo de "colonização" do Centro-oeste e da nova divisão territorial do trabalho agrícola, que tem relação direta com o movimento da "revolução verde" e dos avanços promovidos pelo período técnico-científico-informacional (Santos, 2004), o qual se disseminou de forma desigual pelo território nacional.

Com a expansão das áreas produtivas entre as décadas de 1970 e 1980, regiões como o sul do Piauí, sul do Maranhão e o Oeste da Bahia passaram também a ser abarcadas por esse processo, conhecido como modernização agrícola. Essa ocupação se deu primordialmente em áreas antes não aproveitadas para a agricultura tradicional, devido à baixa fertilidade natural dos solos da região dos Chapadões, as quais, justamente por isso foram adquiridas por preços relativamente baixos, se comparados às outras regiões de fronts já consolidados (Miziara e Ferreira, 2008).

Assim como em todo o Brasil, os solos com maior predominância na região Oeste da Bahia são os latossolos. De acordo com Lepsch (2002), estes são solos típicos de regiões tropicais úmidas, são bem desenvolvidos (profundos) e arenosos, e a fração argilosa é predominantemente de baixa atividade, representada principalmente pela caulinita. Apresentam cores avermelhadas, devido à presença do óxido de ferro em grandes quantidades, e tem boa permeabilidade.

Por suas características químicas acima citadas, os latossolos não são naturalmente aptos para a agricultura. Contudo, suas condições físicas, representadas principalmente pelo relevo plano da região, favorecem 
a agricultura mecanizada, que, agindo conjuntamente com a correção do solo (entre outras técnicas), confere a essa área grande potencial para a prática do agronegócio.

A inserção da cultura do agrobusiness na região Oeste da Bahia engendrou uma nova reestruturação do arranjo territorial, que, sob a égide do capital, tem promovido nas últimas décadas metamorfoses significativas no território do oeste baiano. Como salienta Mondardo (2010, p. 113), "esse processo provocou uma reorganização socioterritorial com a emergência de novas territorialidades por meio da "modernização da agricultura' e do incremento da ascendente urbanização.”

As mudanças mais expressivas ocorridas na região dizem respeito principalmente à esfera econômica e ambiental. Esta última é nitidamente percebida pelo desmatamento indiscriminado que se tem feito nas áreas de Cerrado da Bahia, e não só nesta região, mas em todo o bioma do Cerrado.

Do ponto de vista econômico, a agricultura moderna tem se apresentado como uma via de mão dupla, ora promovendo a região no cenário nacional, como uma das principais responsáveis pela exportação de grãos, ora revelando, em contrapartida, a presença nesse mesmo território de problemas de raízes coloniais, como o trabalho escravo ainda encontrado em alguns lugares no Oeste da Bahia.

É impossível discutir sobre a agricultura moderna no extremo Oeste baiano sem se remeter à estrela do agronegócio, a soja. Áreas antes ocupadas pela pecuária, pela agricultura de subsistência e/ou pela vegetação natural, foram vertiginosamente convertidas em extensos campos de soja, que se perdem de vista no horizonte das planas áreas dos Chapadões dos Gerais.

Segundo Santos Filho (1989, p. 30), “a cultura da soja é a principal forma de penetração da produção agrícola moderna nos cerrados baianos". Mas a produção de outros grãos para exportação também tem se destacado nesta região, como o algodão e o milho, produtos destinados principalmente ao mercado internacional.

Com isso, percebe-se que, a partir dos avanços tecnológicos e da ação conjunta do capital público e privado, áreas antes consideradas improdutivas devido à baixa fertilidade natural dos solos, hoje são palco de uma dinâmica econômica que extrapola as fronteiras nacionais, haja vista a presença hegemônica de empresas multinacionais configurando uma nova territorialização do Oeste baiano. 
Dessa forma, ao analisar os processos históricos que culminaram na atual estruturação espacial dessa região, percebe-se a importância do entendimento das relações entre sociedade e natureza, na construção constante do espaço geográfico, a qual é mediada pela técnica. Mas será que hoje, no meio técnico-científico-informacional, a técnica é autossuficiente na produção do espaço? Ou será que ainda existem resistências locais ou naturais impostas pelo meio, que dificultam a ação da técnica na construção de novos espaços de produção?

De acordo com Milton Santos (2004), a técnica é a grande mediadora entre o homem e o meio, e pode ser conceituada como "um conjunto de meios instrumentais e sociais, com os quais o homem realiza sua vida, produz e, ao mesmo tempo, cria espaço" (Santos, 2004, p. 29). A partir dessa abordagem, consideremos o exemplo de um mapa de solos como uma ferramenta de estratégia, ou uma técnica, que tem como finalidade específica compreender um dado fenômeno, neste caso, o solo.

É nesse contexto que se encaixa a discussão sobre a escala, haja vista ser esta questão inerente ao mapa, e dotada de poder para, a depender do grau de generalização, provocar mudanças na natureza do fenômeno a ser mapeado. A partir de agora então, trataremos da importância desse instrumento (a escala) e sua influência na observação da realidade.

\section{0 problema da escala: mapas "generalistas" que mascaram as peculiaridades}

Quando discutimos sobre escala, é quase impossível deixar de lembrar de uma espécie de "fita métrica" que fica no rodapé dos mapas ou cartas, atributo cartográfico essencial na mediação entre o que é representado no mapa e suas dimensões no real. Caberia então à escala, o papel de generalizar um dado fenômeno com a finalidade de torná-lo visível em sua totalidade.

O conceito de escala tem suas origens na Cartografia, todavia sua aplicabilidade vai muito além dessa ciência. Ainda que não lhe seja um conceito próprio, a Geografia, principalmente a chamada geografia dos estados-maiores, como salienta Yves Lacoste, utilizou-se da escala como "instrumento de poder" na representação formalizada do espaço (Lacoste, 1988, p. 34).

Nesse contexto, observa-se a importância de entender, a priori, o conceito de escala, já que esta é mediadora entre o fenômeno e sua repre- 
sentação, e a depender do nível de análise da escala utilizada, um mesmo fenômeno pode ser representado de diferentes formas. Por isso, é preciso atenção na escolha da escala de representação, já que, dependendo do objeto, determinada escala se faz necessária, pois em outra ele não seria representável ou seu significado seria modificado, como destacou Lacoste (1988).

Este problema básico da escala relacionado ao tamanho (ou a dimensão), que varia do espaço local ao planetário, vai além das fronteiras das Ciências Humanas, gerando debates também na Arquitetura, na Biologia, na Física. Nesta última tem-se o exemplo das discordâncias entre a Teoria da Relatividade Geral e a Mecânica Quântica - a primeira é responsável por descrever a força da gravidade e trabalhar com objetos em escalas planetárias, enquanto a segunda lida com fenômenos extremamente pequenos, em escala manométricas ${ }^{1}$ (Hawking \& Mlodinow, 2005). O problema, neste caso, gira em torno da seguinte questão: a depender da escala de análise determinadas leis (seja da Relatividade ou da Mecânica Quântica) não se aplicam.

No caso da Física, esse debate em torno da escala tem relação não só dimensional, mas fenomenal, já que, a depender do objeto (seja um elétron ou um planeta), determinadas leis não se aplicam, ou seja, "o mecanismo de base não é transferível da escala macroscópica àquela microscópica” (Castro, 1995, p. 131). Por isso, hoje, os físicos não medem esforços na busca de uma nova teoria que seja universalmente aplicada, independente da escala de análise, que incorpore a Teoria da Relatividade Geral e a Mecânica Quântica, o que resultaria em uma “teoria quântica da gravidade”.

Mas quanto às outras ciências? Existe uma preocupação na discussão sobre a escala? No caso da Geografia, disse Yves Lacoste (1988, p. 84): “o problema das escalas é portanto primordial para o raciocínio geográfico”. Todavia, ainda são poucos os trabalhos que discutem esse assunto; em geral estão presos estritamente a discutir a velha dicotomia entre escala cartográfica e escala geográfica, promovendo mais dúvidas do que assertivas sobre o assunto.

Discutindo sobre a escala e a construção do objeto, Bernard Lepetit (1998) afirma que a escala seria o nexo entre um representante, o mapa, e seu referente, o objeto, a superfície, e/ou o espaço. Nas suas palavras ele salienta: 
Mais que uma relação de similitude com o real, a escala designa uma redução dele. Ela exprime uma intenção deliberada de visar a um objeto e indica o campo de referência no qual o objeto é pensado. A adoção de uma escala é antes de mais nada a escolha de um ponto de vista de conhecimento. (Lepetit, 1998, p. 94)

A partir desse raciocínio, coloca-se em evidência mais uma vez a importância da escala, e mais do que isso, a necessidade de se fazer uma escolha, por parte do pesquisador, de qual será a melhor escala para determinado estudo. Infelizmente, em grande parte dos trabalhos a escolha da escala de análise é arbitrária e quase sempre não explicitada (Racine et al., 1983). Essa atitude resulta num segundo problema, o da multiescalaridade, que de acordo com Menezes e Neto (1999, p. 5) diz respeito à "integração de múltiplas escalas em uma única base de informações", desconsiderando que esses diferentes níveis de análises resultam em diferenças quantitativas e qualitativas no resultado final (Lacoste, 1988).

Devemos ter clareza de que o mapa, como forma de representação, tem como função básica reduzir um número de informações e ainda representá-las em sua totalidade. Nesse sentido, a escala se coloca como ferramenta que assegura a noção de proporção entre o que foi mapeado e suas dimensões no real. Essa ideia de redução tem relação direta com outro conceito, o de generalização. Lepetit (1996, p. 79) afirma:

A generalização é procedimento abstrato e processo de abstração: seu resultado se inscreve inteiramente na ordem das representações. Ela opera por seleção dos termos comuns e por perda da singularidade, do detalhe, da diferença concebida como secundária.

Ou seja, independente da escala de análise utilizada, esta não passa de uma representação reduzida e generalizada da realidade. Mas, e quando essa generalização induz a uma informação falaciosa? Ou quando não, mascara informações importantes para análise da realidade representada? Por isso, e mais uma vez, a escolha da escala deve ser enfatizada na pesquisa, com o objetivo de representar o fenômeno da maneira mais fiel possível à sua realidade.

Com relação a esse problema da generalização, tomemos o exemplo dos mapas de solos do Brasil, em destaque os mapeamentos de nível nacional. Diante das dimensões continentais do país, os levantamentos de solos, em escala de detalhe, compatível com a realidade regional/lo- 
cal, ainda se apresentam como um desafio para a Ciência dos Solos. As últimas pesquisas de grande porte, lideradas pelo Serviço Nacional de Levantamento e Conservação de Solos (SNLCS) e pelo Projeto RadamBrasil, ocorreram no ano de 1981 (Ramos, 2003). Vale ressaltar que essas pesquisas, ao final, apresentaram mapeamentos com escalas de 1:5.000.000 e 1:1.000.000, respectivamente. Desse modo, o nível de detalhamento dos tipos de solos era simplificado e, em alguns casos, solos diferentes de uma determinada área eram generalizados como estando num mesmo nível taxonômico.

Como já foi discutido anteriormente, a generalização faz parte do processo de representação, mas é preciso ter cuidado para que esse retrato da realidade, no caso o mapa, não induza a uma informação falsa, a um simulacro. O papel da escala é crucial, porque influencia no grau de generalização e/ou de especificidade na representação.

A partir de agora trataremos neste artigo de um estudo de caso que exemplifica essa problemática em torno da escala dos mapas de solos do Brasil, que são na sua grande maioria generalistas, muitas vezes incompatíveis com a realidade local, mascarando particularidades - nesse caso, os solos coesos no Oeste da Bahia. A partir daí, discutiremos como a presença desse solo atípico determina resistência do meio à incorporação de novas áreas pela agricultura moderna, hoje hegemônica nesta região.

\section{Estudo de caso: manejo de solos coesos no Oeste da Bahia}

Estudos realizados sobre a ocorrência de solos coesos no Brasil datam de 1950, quando, em pesquisas no estado do Rio de Janeiro, foram encontrados solos com determinadas características, tais como: alto grau de consistência (coesão), quando secos, e friáveis, quando úmidos (Giarola, 2002).

Em meados do ano de 1970, pesquisas exploratórias realizadas no estado do Espírito Santo confirmaram a ocorrência de solos com as mesmas características, o que levou à inserção da categoria "caráter coeso" do solo ao Sistema Brasileiro de Classificação de Solos (SiBCS). Caracterizado de acordo com critérios de Jacomine (2001), Ribeiro (2001) e Santos et al. (2005), o "caráter coeso" é

usado para distinguir solos com horizontes pedogenéticos subsuperficiais adensados, muito resistentes à penetração da faca e muito 
duros a extremamente duros quando secos, passando a friáveis ou firmes quando úmidos. (Embrapa, 2009, p. 42)

Atualmente, ainda se discute sobre quais fatores teriam propiciado a formação de solos com horizontes coesos. Entre os possíveis condicionantes na gênese desse tipo de solo, estaria: "o agrupamento das partículas de argilas face a face, a perda de plasma argiloso na camada superficial para as subjacentes (argiluviação), ou ainda, a presença de compostos orgânicos poucos polimerizados” (Lima, 2004, p. 1).

Além das polêmicas com relação à origem e evolução dos solos coesos, muito se discute sobre as formas de manejo para esses tipos de solo, os quais, pelas suas próprias características, se apresentam como limitantes ao uso agrícola. Entre os problemas no manejo dos solos coesos, Lima (2004) menciona a elevada resistência à penetração, como o principal limitador, tanto no aspecto físico como químico do solo. De acordo com o autor,

dos problemas relacionados com o caráter coeso, pode-se citar a elevada resistência à penetração do solo quando seco, que influencia: (a) o desenvolvimento radicular das plantas, (b) o teor de água disponível e (c) a aeração e a absorção de nutrientes, constituindo um inibidor físico que pode afetar a produção agrícola. (Lima, 2004, p. 498)

Hoje, é possível identificar a ocorrência desses solos em aproximadamente dez milhões de hectares, só no Nordeste brasileiro (Rezende, 2000). Não obstante, na região Sudeste, também foram identificados solos com as mesmas características, geralmente localizados nas áreas planas dos topos dos tabuleiros, formados a partir dos sedimentos do Grupo Barreiras (Fonseca, 1986).

De acordo com a literatura citada, a ocorrência deste tipo de solo estaria limitada principalmente às áreas litorâneas dos tabuleiros costeiros, no Sudeste e no Nordeste brasileiro. Entretanto, estudos recentes na região do Oeste da Bahia identificaram solos com horizonte coeso, mais especificamente, Latossolos Amarelo Distrocoeso Plíntico, solos alóctones formados a partir de sedimentos do Quaternário (Alves, 2011; Brasil, 2011). Assim, pode-se considerar esse tipo de solo como uma anomalia, ou seja, como um solo atípico para a região, já que não foram identificados em mapeamentos anteriores. 
A identificação desse tipo de solo na região se deu a partir do mapeamento da folha SC 23-Z-C-II-3-S0 (Figura 1), na escala de 1:25.000, localizada entre os limites de uma fazenda experimental da empresa Gestão Empreendimentos Florestais (GRANFLOR). Nesta fazenda desenvolvem-se experimentos com plantação de milho, algodão, soja e eucalipto. Entre essas culturas, parte da produção de eucalipto apresentou problemas no desenvolvimento radicular, chegando a casos de mortandade da espécie.

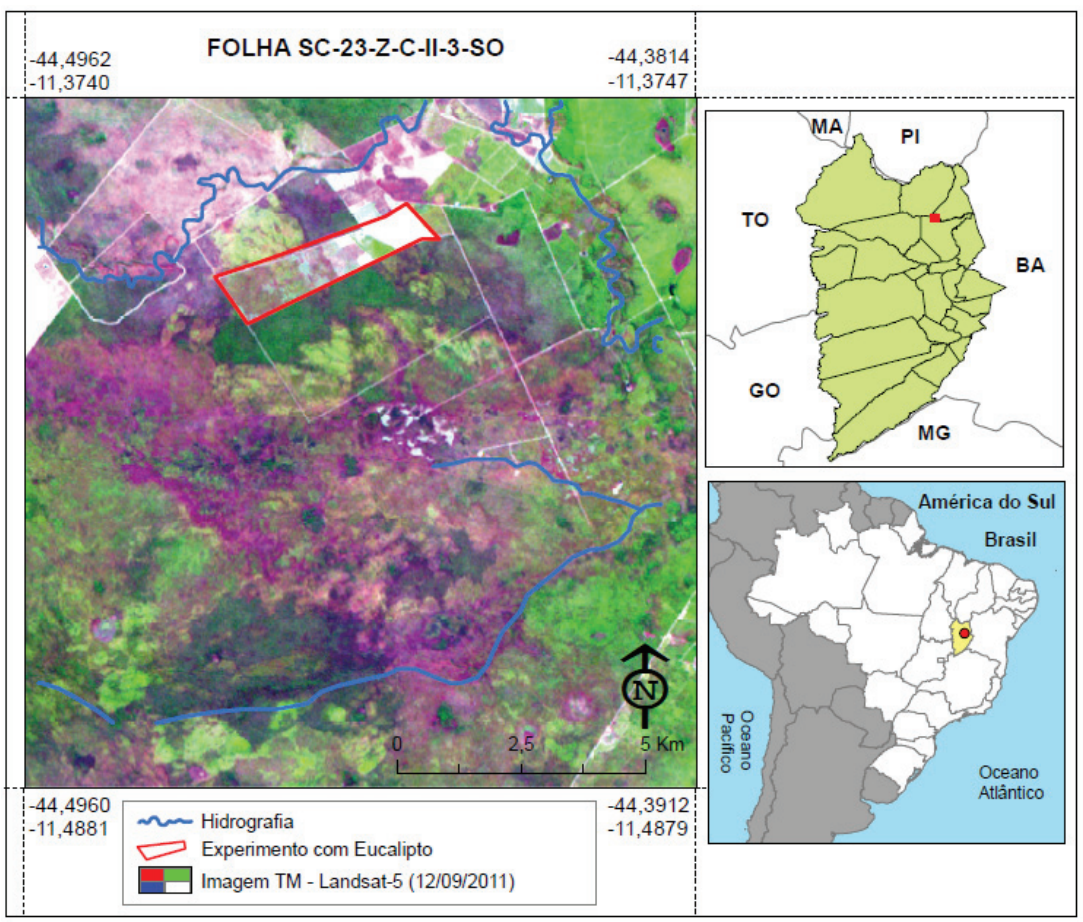

Figura 1 - Mapa de localização da folha SC 23-Z-C-II-3-SO.

Fonte: Elaboração por Joildes Brasil (2012).

O problema com a plantação de eucalipto despertou o interesse dos gestores da fazenda em investigar se a causa da mortandade seria determinada por características pedológicas. A partir do trabalho de revisão bibliográfica, coleta das amostras de solos, ${ }^{2}$ análise em laboratório ${ }^{3}$ e tratamento estatístico, foi possível a confecção do mapa de solos da carta SC 
23-Z-C-II-3-S0, na escala de 1:25.000. Assim, foram identificados exatos três tipos de solos: Latossolo Amarelo Distrófico típico, Latossolo Amarelo Distrocoeso plíntico e Neossolo Quartzarênico Órtico latossólico. Esse resultado se contrapõe à informação oficial, que representa essa área como detentora de um único tipo de solo, o Latossolo Vermelho-Amarelo Distrófico (Embrapa, 1999), conforme se observa na Figura 2.

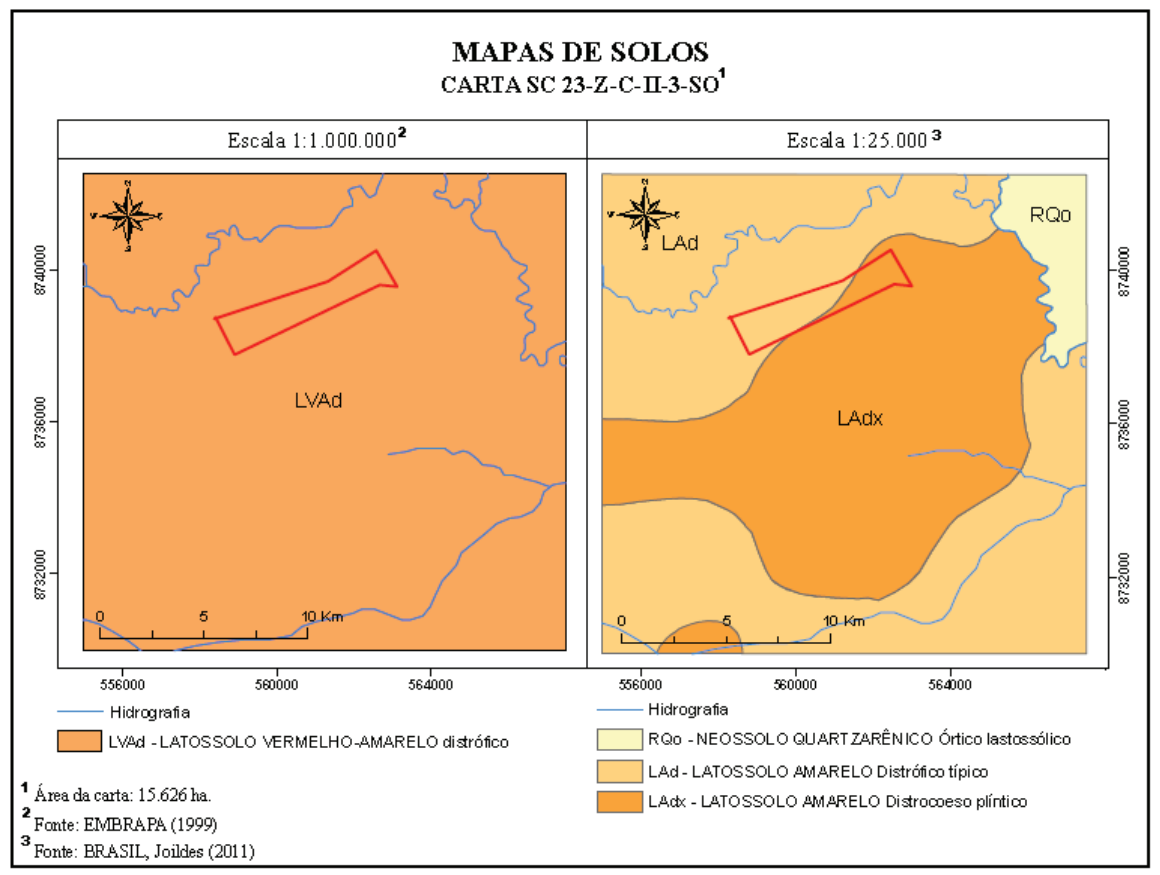

Figura 2 - Comparação entre os mapas de solos da carta SC 23-Z-C-II-3-S0.

Fonte: Elaboração por Joildes Brasil (2012).

Com base na figura anterior é seguro reafirmar que, a depender da escala, o fenômeno observado apresenta mudanças na sua representação. No caso estudado, os detalhes descartados pelo mapeamento de pequena escala apresentado pela Embrapa, acabou mascarando peculiaridades relevantes do solo local, interferindo diretamente no uso e apropriação dessa área. A presença dos solos coesos (especificamente, os Latossolos Amarelo Distrocoeso plíntico) foram a causa do mau desempenho de parte do plantio de eucalipto nessa área. 
A formação do horizonte coeso no solo é, por si só, um limitante natural no desenvolvimento das plantas, no sentido de que se apresenta extremamente resistente à penetração das raízes (quando secos) e, em períodos chuvosos, está sujeito a um processo de saturação do solo, engendrando problemas de aeração, como anoxia. ${ }^{4}$

No caso do plantio do eucalipto, nas áreas onde ocorre o solo coeso (geralmente entre os 20 a $150 \mathrm{~cm}$ de profundidade), as raízes, por não conseguirem ultrapassar a camada adensada, tendem à horizontalização, deixando a planta mais frágil diante de intempéries naturais (Figura 3).

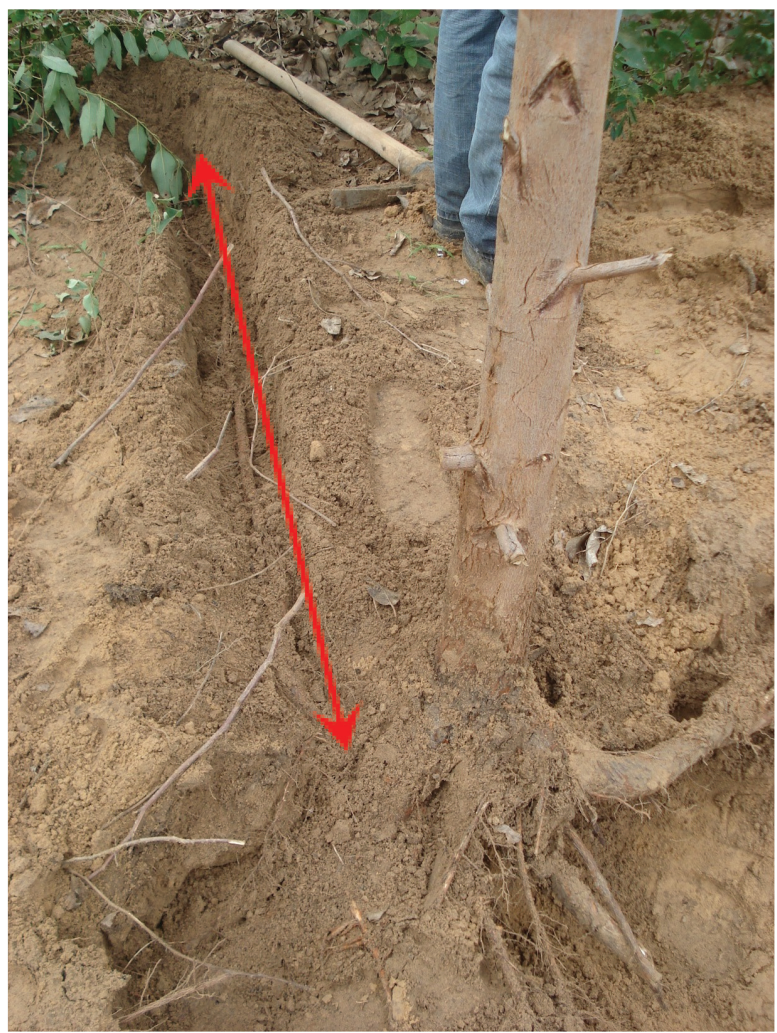

Figura 3 - Foto de um eucalipto vivo cultivado em solo coeso. Observa-se que a raiz cresce na horizontal, muito próxima à camada superficial do solo, o que pode causar instabilidade à planta e problema na troca de nutrientes.

Fonte: Elaboração por Joildes Brasil (2012). 
Mesmo diante de suas limitações pedogenéticas, os solos coesos da região litorânea do Brasil são comumente utilizados para cultivo, com destaque para a cana-de-açúcar (Silva et al. 2006). No caso da fazenda analisada, os solos coesos só se apresentaram como resistência para a cultura do eucalipto, já que as raízes dessa planta precisam alcançar maior profundidade para se estabilizar; e não conseguindo penetrar a camada adensada, tendem à horizontalização. Nas áreas com outros tipos de cultura, como milho, algodão e soja, a presença do horizonte coeso não comprometeu o cultivo, por estar assentado em camadas mais profundas do solo.

Todavia, deve ser salientado que a identificação dessa camada endurecida não é uniforme no perfil do solo de todas as áreas com essa característica, variando desde muito próximo à superfície, entre os primeiros 10 e $20 \mathrm{~cm}$ do solo, em algumas áreas, até os $100 \mathrm{~cm}$ de profundidade em outras. Nesse sentido, no caso de novas áreas serem incorporadas ao cultivo, mesmo na cultura de grãos, cujas raízes são mais rasas, existem grande chances de o solo se apresentar como um limitador ou, pelo menos, como uma resistência local natural, principalmente quando esse horizonte coeso está localizado muito próximo à superfície.

\section{Considerações finais}

Como discutido ao longo do artigo, dependendo da escala de análise adotada, a realidade será representada de diferentes formas. Não que haja uma escala universal, ou que esta escala adequada represente o apanágio do pesquisador, como disse Lepetit (1998). A escolha da escala na pesquisa deve ser uma decisão tomada pelo autor da pesquisa, que vai deliberar com base em sua intenção e no nível de análise desejado.

A identificação de solos coesos numa região em que, de acordo com os mapas de solos disponíveis, não os possuía, diz respeito diretamente à escala utilizada por estes mapeamentos. No caso dos mapas atuais, no Brasil são utilizadas escalas de 1:5.000.000 e 1:1.000.000, o que reflete uma generalização exacerbada, que se afasta da efetiva realidade local.

Diante da expansão agrícola que se observa na região Oeste da Bahia, a presença dos solos coesos identificados nesta pesquisa, ainda que de forma pontual, expressam uma resistência à agricultura, haja vista, suas limitações físico-químicas, representadas principalmente pela 
presença de uma camada extremamente compacta, a qual inibe o crescimento radicular.

Conclui-se que, ainda que o problema tenha se manifestado estritamente na plantação dos eucaliptos, devido à necessidade de suas raízes atingirem maior profundidade, deve ser levado em consideração que, mesmo culturas de grãos (como soja, milho, algodão), que concentram suas raízes muito próximas à superfície, se plantadas sobre solos coesos onde a camada adensada esteja entre os primeiros centímetros, elas também, muito provavelmente, apresentarão problemas na plantação.

\section{Notas}

1. Milionésimo de milionésimo.

2. Foram coletadas amostras de trinta e seis pontos da carta SC 23-Z-C-II-3-SO, com distância de $2,5 \mathrm{~km}$ entre cada ponto. Ao longo do perfil do solo foram coletadas amostras com variação de $50 \mathrm{~cm}$, desde a amostra superficial $(0 \mathrm{~cm})$ até a de $200 \mathrm{~cm}$ de profundidade.

3. Para a classificação dos tipos de solos da carta estudada, foram realizadas as seguintes análises laboratoriais: textura, argila dispersa, floculação, relação silte/argila, pH (H2O e KCl), delta pH e PCZ (Ponto de Carga Zero).

4. A anoxia é conhecida como o processo de ausência total de oxigênio no solo, o que intensifica o estresse radicular.

\section{Referências}

AB'SÁBER, A. N. Os domínios da natureza no Brasil: potencialidades paisagísticas. 4. ed. São Paulo: Ateliê, 2007.

ALVES, R. R. Gênese e evolução da paisagem quaternária no médio São Francisco: fatos e evidências na bacia do rio Grande-Bahia. 298f. Tese (Doutorado em Geografia) - Universidade Federal de Uberlândia, Uberlândia, MG, 2011.

BRASIL, J. Classificação e mapeamento de solos na depressão do São Francisco, $B A$ : carta SC 23-Z-C-II-3-SO. 96f. Monografia (Graduação em Geografia) Universidade Federal da Bahia, Barreiras, BA, 2011.

CASTRO, I. E. O problema da escala. In: CASTRO, I. E.; GOMES, P. C. C.; CORRÊA, R. L. (Orgs.). Geografia: conceitos e temas. Rio de Janeiro: Bertrand Brasil, 1995.

EMPRESA BRASILEIRA DE PESQUISA (Embrapa). Centro Nacional de Pesquisa de Solos. Sistema Brasileiro de Classificação de Solos. Brasília, DF: Embrapa Produção de Informação; Rio de Janeiro: Embrapa, 2009.

FONSECA, O. O. M. Caracterização e classificação de solos latossólicos e podzólicos desenvolvidos nos sedimentos do Terciário no litoral brasileiro. 185p. 
Dissertação (Mestrado) - Universidade Federal Rural do Rio de Janeiro, Itaguaí, RJ, 1986.

FREDERICO, S. O novo tempo do cerrado: expansão dos fronts agrícolas e controle do sistema de armazenamento de grãos. Tese (Doutorado em Geografia Humana) - Faculdade de Filosofia, Letras e Ciências Humanas, Universidade de São Paulo, São Paulo, 2009.

GIAROLA, N. F. B.; SILVA, A. P. Conceitos sobre solos coesos e Hardsetting. Scientia Agricola, Piracicaba, SP, ESALQ, v. 59, n. 3, p. 613-620, jul./set., 2002.

HAESBAERT, R. "Gaúchos” e baianos no "novo” Nordeste: entre a globalização econômica e a reinvenção das identidades territoriais. In: CASTRO, I. E. de; GOMES, P. C. da C.; CORRÊA, R. L. (Orgs.). Brasil: questões atuais da reorganização do território. Rio de Janeiro: Bertrand Brasil, 1996. p. 367-418.

HAWKING. S.; MLODINOW, L. Uma nova história do tempo. Tradução de Vera de Paula Assis. Rio de Janeiro: Ediouro, 2005.

LACOSTE, Yves.uA Geografia - isso serve, em primeiro lugar, para fazer a Guerra. 13. ed. Campinas, SP: Papirus. 1988.

LEPETIT, B. Sobre a escala na história. In: REVEL, J. (Org.). Jogos de escalas: a experiência da microanálise. Tradução de Dora Rocha. Rio de Janeiro: Fundação Getúlio Vargas, 1998.

LEPSCH, Igo F. Formação e conservação dos solos. 1. ed. São Paulo: Oficina de Textos, 2002.

LIMA, A. W. R. S. Subsídios para um sistema de gestão ambiental de projetos de reflorestamento com Eucalyptus sp na região do litoral norte do estado da Bahia. Dissertação (Mestrado em Desenvolvimento Sustentável) - Universidade de Brasília, Brasília, 2004.

MENEZES, P. M. L; COELHO NETTO, A. L. Escala: estudo de conceitos e aplicações. In: Anais do XIX Congresso Brasileiro de Cartografia, Recife, CD ROM, 1999.

MIZIARA, F.; FERREIRA, N. C. Expansão da fronteira agrícola e evolução da ocupação e uso do espaço no Estado de Goiás - subsídios à política ambiental. In: GUIMARÃES, L. F. (Org.) A encruzilhada socioambiental: biodiversidade, economia e sustentabilidade no cerrado. Goiânia: Ed. UFG, 2008.

MONDARDO, M. L. A “territorialização” do agronegócio globalizado em Barreiras, BA: migração sulista, reestruturação produtiva e contradições socioterritoriais. Revista Nera, ano 13, n. 17, p. 113-130, jul./dez., 2010.

RACINE, J. B.; RAFFESTIN, C.; RUFFY, V. Escala e ação, contribuição para uma interpretação do mecanismo de escala na prática da Geografia. Revista Brasileira de Geografia, Rio de Janeiro, v. 45, n. 1, p. 123-135, jan./mar., 1983.

RAMOS, D. P. Desafios da pedologia brasileira frente ao novo milênio. Palestra proferida no XXIX Congresso Brasileiro de Ciência do Solo. Ribeirão Preto, SP, 2003.

REZENDE, J. O. Solos coesos dos tabuleiros costeiros: limitações agrícolas e manejo. SEAGRI, SPA, 2000. 117p. (Série Estudos Agrícolas, 1). 
SANTOS, M. A natureza do espaço: técnica e tempo, razão e emoção. 4. ed. São Paulo: Edusp, 2004.

SANTOS FILHO, M. O processo de urbanização no Oeste baiano. Recife: SudeneDPG, PSU-URB, 1989.

SILVA, A. J. N.; CABEDA, M. S. V.; CARVALHO, F. G. Matéria orgânica e propriedades físicas de um Argissolo Amarelo Coeso sob sistemas de manejo com cana-de-açúcar. Revista Brasileira de Engenharia Agrícola Ambiental, v. 10, p. 579-585, 2006.

Joildes Brasil - Possui Bacharelado em Geografia pela Universidade Federal da Bahia. Atualmente é Mestranda em Geografia pela Universidade Federal de Goiás.

Recebido para publicação em 17 de novembro de 2012 Aceito para publicação em 25 de fevereiro de 2013 